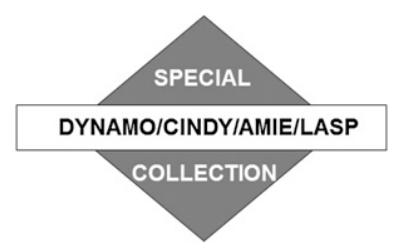

\title{
Moist Static Energy Budget of the MJO during DYNAMO
}

\author{
ADAM SOBEL \\ Department of Applied Physics and Applied Mathematics, and \\ Lamont-Doherty Earth Observatory, Columbia University, \\ New York, New York \\ SHUGUANG WANG \\ Department of Applied Physics and Applied Mathematics, \\ Columbia University, New York, New York \\ DAEHYUN KIM \\ Department of Atmospheric Sciences, University of Washington, Seattle, Washington
}

(Manuscript received 27 February 2014, in final form 25 July 2014)

\begin{abstract}
The authors analyze the column-integrated moist static energy budget over the region of the tropical Indian Ocean covered by the sounding array during the Cooperative Indian Ocean Experiment on Intraseasonal Variability in the Year 2011 (CINDY2011)/Dynamics of the Madden-Julian Oscillation (DYNAMO) field experiment in late 2011. The analysis is performed using data from the sounding array complemented by additional observational datasets for surface turbulent fluxes and atmospheric radiative heating. The entire analysis is repeated using the ECMWF Interim Re-Analysis (ERA-Interim). The roles of surface turbulent fluxes, radiative heating, and advection are quantified for the two MJO events that occurred in October and November using the sounding data; a third event in December is also studied in the ERA-Interim data.

These results are consistent with the view that the MJO's moist static energy anomalies grow and are sustained to a significant extent by the radiative feedbacks associated with MJO water vapor and cloud anomalies and that propagation of the MJO is associated with advection of moist static energy. Both horizontal and vertical advection appear to play significant roles in the events studied here. Horizontal advection strongly moistens the atmosphere during the buildup to the active phase of the October event when the lowlevel winds switch from westerly to easterly. Horizontal advection strongly dries the atmosphere in the wake of the active phases of the November and December events as the westerlies associated with off-equatorial cyclonic gyres bring subtropical dry air into the convective region from the west and north. Vertical advection provides relative moistening ahead of the active phase and drying behind it, associated with an increase of the normalized gross moist stability.
\end{abstract}

\section{Introduction}

Though the Madden-Julian oscillation (MJO) was first discovered over four decades ago (Madden and Julian 1971, 1972; Julian and Madden 1981), its basic dynamics remain unexplained to the collective satisfaction of the research community. There is no

Corresponding author address: Adam Sobel, Columbia University, Dept. of Applied Physics and Applied Mathematics, $500 \mathrm{~W}$. 120th St., Rm. 217, New York, NY 10027.

E-mail: ahs129@columbia.edu fundamental agreement on what kind of dynamical entity the MJO is.

We have been pursuing the notion that the MJO is a moisture mode. At the broadest level, we mean by this a mode of variability that would not exist in any mathematical model that does not contain a prognostic equation for moisture. At this level of generality, the idealized models of Sobel and Maloney (2012, 2013) depict moisture modes, as do those of Fuchs and Raymond (2002, 2005, 2007), Majda and Stechmann (2009), Sugiyama (2009a,b), Sukhatme (2014), and perhaps others. 
More specifically, we have been led by analysis of observations and comprehensive models to the view that the interaction of the MJO's convection and circulation anomalies with energy fluxes at the boundariessurface turbulent fluxes and radiative fluxes-is important to its growth and maintenance (e.g., Sobel et al. 2008, 2010; see also Emanuel 1987; Neelin et al. 1987; Raymond 2001; Bony and Emanuel 2005). This view follows earlier theoretical and modeling studies which posited that the MJO might be driven by feedbacks involving surface turbulent fluxes (Emanuel 1987; Neelin et al. 1987) or radiative fluxes (Raymond 2001; Bony and Emanuel 2005). Since these processes are sources and sinks of column-integrated moist static energy (MSE) or moist entropy, this view suggests that it may be useful to view the observed MJO through columnintegrated budgets of these conserved variables. It is also a durable principle in the physical sciences that it is often useful to study any phenomenon from the point of view of those variables that are most nearly conserved.

In this study, we analyze the column-integrated moist static energy budget of a region in the tropical Indian ocean during a single season of MJO activity, namely, that of the Cooperative Indian Ocean Experiment on Intraseasonal Variability in the Year 2011 (CINDY2011)/ Dynamics of the MJO (DYNAMO) field campaign (Zhang et al. 2013; Yoneyama et al. 2013; Gottschalck et al. 2013). We choose this period because of the availability of high-quality radiosonde observations from the array put in place for the campaign. Also, there is value in focusing on a small number of events, even though the conclusions necessarily lack the generality associated with statistical analyses of longer records.

Our expectations, based on previous work (e.g., Sobel et al. 2008, 2010; Maloney 2009; Kiranmayi and Maloney 2011; Ma and Kuang 2011; Andersen and Kuang 2012; Kim et al. 2014) are the following.

1) Precipitation and column-integrated MSE are approximately in phase [or MSE leads slightly (e.g., Yasunaga and Mapes 2012)].

2) Radiative heating is approximately in phase with both column-integrated MSE and precipitation (Lin and Mapes 2004).

3) Surface turbulent fluxes (latent being the dominant one, sensible being small) are positively correlated with MSE, but with some phase lag.

4) Vertical advection is approximately out of phase with MSE; since positive moist static energy anomalies are associated with ascent, this implies that the gross moist stability (Neelin and Held 1987; Raymond et al. 2009) is positive.

5) Horizontal advection leads MSE, perhaps being close to in quadrature, so that it has the effect of aiding propagation. That is, we expect horizontal advection to provide moistening ahead (to the east) of the active phase, drying behind (to the west of) the active phase, or both.

6) Neither vertical nor horizontal advection is positively correlated with MSE itself, while radiative and turbulent fluxes are; thus, radiative and turbulent fluxes are responsible for the growth and maintenance of the MSE anomalies associated with the MJO.

Of these expectations, the last two, involving advection, are the most uncertain. The gross moist stability is difficult to estimate from observations, even in sign, and even in the climatological mean (e.g., Back and Bretherton 2006). Raymond and Fuchs (2009) obtain better MJO simulations in models whose gross moist stabilities are negative and infer that it is negative in the real atmosphere. Benedict et al. (2014) similarly found that stronger MJOs were simulated in models with small or negative values of the normalized gross moist stability [NGMS, defined as the moist static energy export divided by either moisture convergence or dry static energy export, and generally the same in sign as the unnormalized gross moist stability; see Raymond et al. (2009) for thorough discussion], but they also found evidence that these small or negative NGMS values are inconsistent with observations. While negative NGMS would allow vertical advection to induce or maintain MSE anomalies and thus strengthen the MJO, vertical advection may also play a role in propagation. If frictional convergence is important to the MJO (e.g., Wang 1988), it is likely to be associated with shallow ascent and moist static energy import in the easterly region, leading the active phase to the east and inducing its eastward propagation.

Our analysis uses observations from the field program as well as routinely available datasets to estimate terms in the moist static energy budget for the region of the CINDY/DYNAMO array for a 3-month period during the experiment. Plots of the time series of these terms from the European Centre for Medium-Range Weather Forecasts (ECMWF) Interim Re-Analysis (ERA-Interim, hereafter ERA-I; Dee et al. 2011) are also examined. Discussion of these time series is complemented by synoptic maps of satellite-derived column water vapor, precipitation, and low-level horizontal flow. 


\section{Data and methods}

\section{a. Data}

The averaged atmospheric state variables derived from the Colorado State University array-averaged analysis products (version 1; Johnson and Ciesielski 2013; Ciesielski et al. 2014) are used here to compute the horizontal and vertical advection of column-integrated moist static energy. We analyze data from the northern sounding array (NSA), located mostly north of the equator in the central equatorial Indian Ocean, as that was the site of greater variability in deep convection during the course of the experiment than was the southern array. The stations of the NSA were Gan Island, Maldives $\left(0.69^{\circ} \mathrm{N}, 73.51^{\circ} \mathrm{E}\right)$; the $\mathrm{R} / \mathrm{V}$ Revelle $\left(0.00^{\circ}\right.$, $\left.80.50^{\circ} \mathrm{E}\right)$; Colombo, Sri Lanka $\left(6.91^{\circ} \mathrm{N}, 79.87^{\circ} \mathrm{E}\right)$; and Malé, Maldives $\left(4.91^{\circ} \mathrm{N}, 73.53^{\circ} \mathrm{E}\right)$; a map is shown in Fig. 1 of Johnson and Ciesielski (2013).

The boundary fluxes of MSE at the surface and top of the atmosphere are estimated from two independent datasets: 1) radiative fluxes averaged over the sounding array from the $1^{\circ}$ daily Clouds and the Earth's Radiant Energy System (CERES; Wielicki et al. 1996; Loeb et al. 2012) SYN1deg data and 2) daily $1^{\circ}$ surface enthalpy fluxes from the objectively analyzed air-sea fluxes (OAFlux) data (Yu et al. 2008).

For comparison, ERA-I (Dee et al. 2011), interpolated to $2.5^{\circ}$ resolution from its original $1.25^{\circ}$, is also used to compute the column-integrated MSE budget terms, as well as the gross moist stability.

Two precipitation datasets are used: the 3-hourly $0.25^{\circ}$ Tropical Rainfall Measuring Mission (TRMM) 3B42 version 7A and the daily Global Precipitation Climatology Project, version 1.2 (GPCPv1.2; Adler et al. 2003; Huffman et al. 2009). Total precipitable water estimated from satellite observations - a combination of the Special Sensor Microwave Imager (SSM/I) and TRMM Microwave Imager (TMI) — is compared against sounding array values and the ERA-I dataset.

\section{b. Methods}

The budget of the column-integrated MSE is computed as

$$
\begin{aligned}
\left\langle\frac{\partial\left(c_{p} T+L_{v} q\right)}{\partial t}\right\rangle= & -\left\langle\mathbf{u} \cdot \nabla\left(c_{p} T+L_{v} q\right)\right\rangle \\
& -\left\langle\omega \frac{\partial h}{\partial p}\right\rangle+E+H+R,
\end{aligned}
$$

where $h$ denotes moist static energy,

$$
h \equiv c_{p} T+L_{v} q+g z
$$

where $T$ is temperature; $q$ is specific humidity; $c_{p}$ is dry air heat capacity at constant pressure $\left(1004 \mathrm{~J} \mathrm{~K}^{-1} \mathrm{~kg}^{-1}\right)$; $L_{v}$ is latent heat of condensation (taken constant at $2.5 \times$ $\left.10^{6} \mathrm{~J} \mathrm{~kg}^{-1}\right)$; $\mathbf{u}$ and $\omega$ are horizontal and pressure vertical velocities, respectively; angle brackts represents massweighted vertical integration from 1000 to $100 \mathrm{hPa}$; $E$ and $H$ are turbulent latent and sensible heat fluxes; and $R$ is column net radiative heating, defined as the difference between the net fluxes at the bottom and top of the atmosphere (thus, we neglect any net radiative heating above $100 \mathrm{hPa}$ ).

Note that the partial time derivative and horizontal advection terms in (1) are applied not to $h$, but to $c_{p} T+$ $L_{v} q$, omitting the $g z$ term. This is consistent with the primitive equations (Neelin 2007). On the other hand Betts (1974), without appealing to the primitive equations, shows that neglecting kinetic energy generation [an assumption also required to derive (1)] and assuming hydrostatic balance together with the first law of thermodynamics results in retention of the $g z$ term in the tendency and horizontal advection. We have tried both forms and found only small differences. [The form of (1) leads to slightly better closure of the budgets, discussed further in the presentation of Figs. 8 and 9 below.] The dry static energy equation is

$$
\left\langle\frac{\partial s}{\partial t}\right\rangle=-\langle\mathbf{u} \cdot \nabla s\rangle-\left\langle\omega \frac{\partial s}{\partial p}\right\rangle+H+R+L_{v} P
$$

where $s \equiv c_{p} T+g z$ is dry static energy and $P$ is precipitation.

The total normalized gross moist stability (e.g., Raymond et al. 2009), here denoted $\tilde{M}_{t}$, may be directly estimated as

$$
\tilde{M}_{t}=\frac{\left\langle\omega \frac{\partial h}{\partial p}\right\rangle+\langle\mathbf{u} \cdot \nabla h\rangle}{\left\langle\omega \frac{\partial s}{\partial p}\right\rangle} .
$$

Our choice of column-integrated vertical advection of dry static energy in the denominator follows Sobel and Maloney (2012, 2013); Raymond et al. (2009), for example, normalize by the moisture convergence. In practice, the difference is minor. By either definition, $\tilde{M}_{t}$ quantifies the relationship between the precipitation and the net column forcing of MSE (surface fluxes plus radiation) in steady state, with smaller NGMS giving greater steady-state precipitation for a given net positive forcing. If we assume steady state and neglect horizontal advection of dry static energy in (2), then that equation 


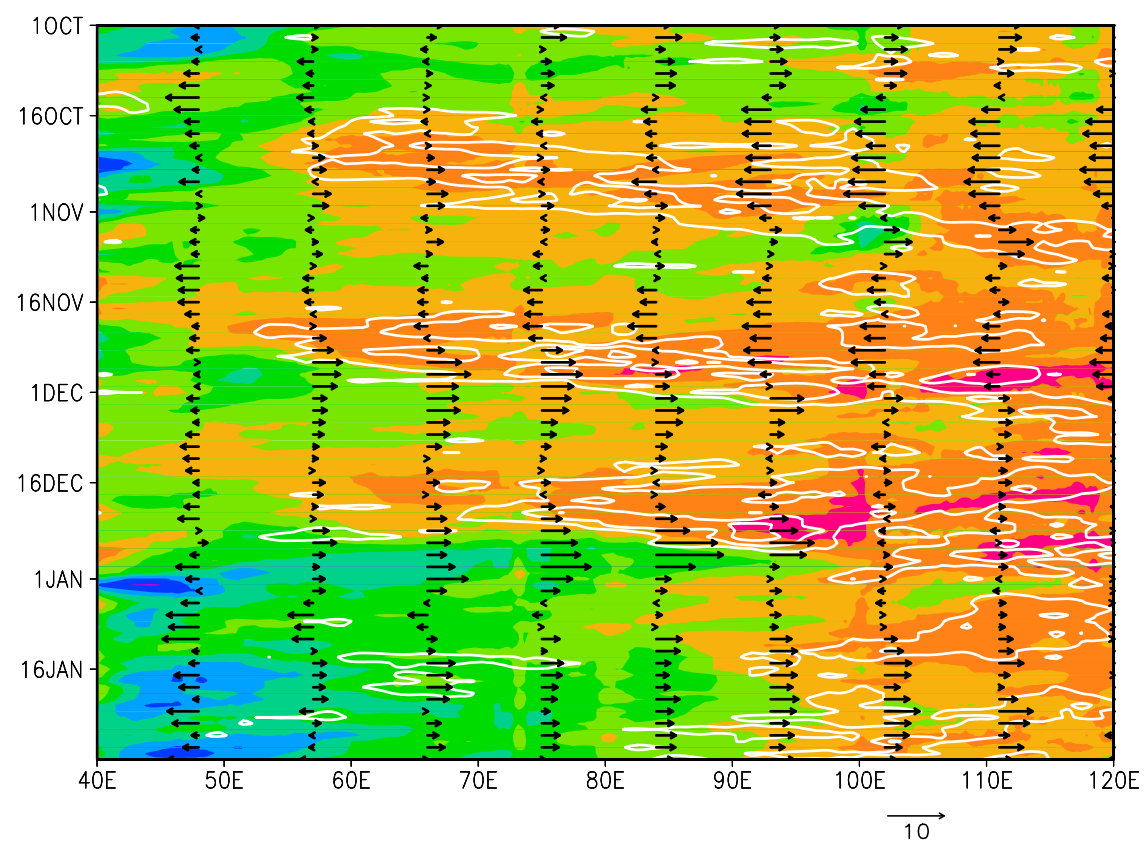

25

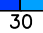

35

40

FIG. 1. Hovmöller diagram of $10^{\circ} \mathrm{S}-10^{\circ} \mathrm{N}$-averaged precipitable water (mm, shaded), precipitation (mm day ${ }^{-1}$, contours), and $850-\mathrm{hPa}$ zonal wind ( $\mathrm{m} \mathrm{s}^{-1}$, arrows) during the CINDY/ DYNAMO period. The first contour represents $10 \mathrm{~mm} \mathrm{day}^{-1}$ and the contour interval is $10 \mathrm{~mm} \mathrm{day}^{-1}$.

together with (1) can be solved for precipitation using the definition of $\tilde{M}_{t}$ :

$$
L_{v} P=\tilde{M}_{t}^{-1}(E+H+R)-R-H .
$$

In the transient case, smaller NGMS leads to a greater positive tendency of $\langle h\rangle$ for a given positive forcing, while negative $\tilde{M}$ gives a positive tendency of $\langle h\rangle$ even when forcing is negative. We use the subscript $t$ to indicate that (3) defines the "total" NGMS, including both horizontal and vertical advection terms in the numerator. Horizontal and vertical components may be defined separately by retaining only one or the other in the numerator. The quantity denoted $\tilde{M}$ in Sobel and Maloney $(2012,2013)$ is the vertical component.

The direct use of (3) requires computation of the advection terms. The vertical advection term in particular is delicate. It depends closely on the vertical motion profile, which is a relatively highly derived quantity containing considerable uncertainty, and there is generally significant cancellation in the vertical integral. We complement this direct calculation by an alternate method in which we ignore time tendency and horizontal advection of dry static energy in (2) but retain the tendency and horizontal advection terms in (1) and then estimate the NGMS indirectly as

$$
\tilde{M}_{t}=\frac{E+H+R-\left\langle\left(\frac{\partial}{\partial t}+\mathbf{u} \cdot \nabla\right)\left(c_{p} T+L_{v} q\right)\right\rangle}{H+R+L_{v} P} .
$$

\section{Results}

We first examine several time series that provide useful context to our investigation of the MSE budget. In each case more than one dataset is used, to give a sense of the observational uncertainties.

Figure 1 is a Hovmöller plot of column-integrated water vapor $(\mathrm{mm})$, precipitation from $\operatorname{GPCP}\left(\mathrm{mm} \mathrm{day}^{-1}\right)$, and anomalous zonal wind at $850 \mathrm{hPa}\left(\mathrm{m} \mathrm{s}^{-1}\right)$, all averaged between $10^{\circ} \mathrm{S}$ and $10^{\circ} \mathrm{N}$, as functions of time and longitude. Three MJO events are readily apparent as eastward-propagating maxima in the water vapor and precipitation. The first two occurred during the operation of the sounding array. Further discussion of the large-scale context and synoptic evolution of these events can be found in, for example, Yoneyama et al. (2013), Gottschalck et al. (2013), Johnson and Ciesielski (2013), and Kerns and Chen (2014). The properties of the cloud populations as characterized by radar and other observations are presented in Powell and Houze (2013) and Zuluaga and Houze (2013). In each event 
Northern array $(73-80 \mathrm{E}, \mathrm{Eq} .-5 \mathrm{~N})$

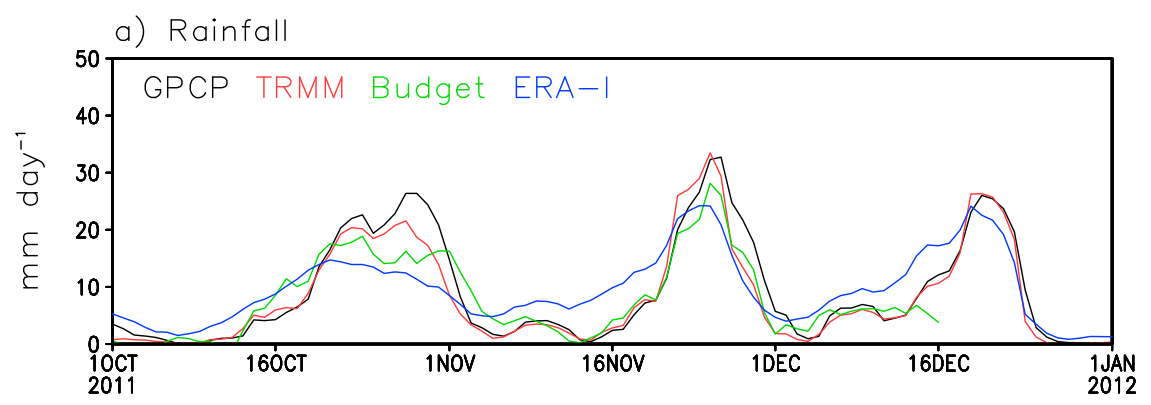

b) Precipitable water

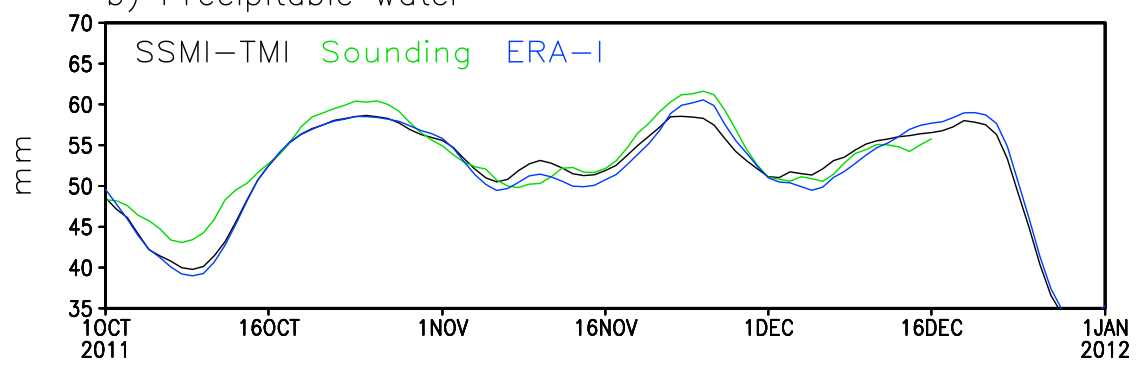

c) Column integrated MSE

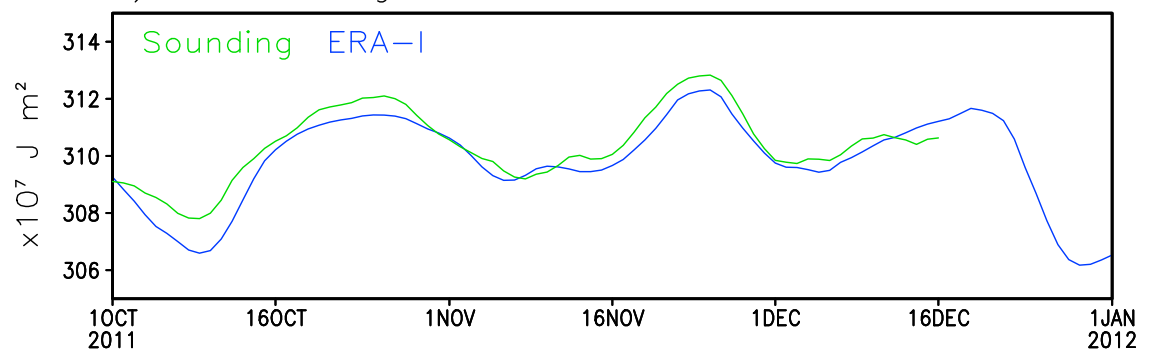

FIG. 2. Area-averaged $\left(0^{\circ}-5^{\circ} \mathrm{N}, 73^{\circ}-80^{\circ} \mathrm{E}\right)$ time series of (a) rainfall $\left(\mathrm{mm} \mathrm{day}^{-1}\right)$, (b) precipitable water $(\mathrm{mm})$, and (c) column-integrated MSE $\left(\times 10^{7} \mathrm{~J} \mathrm{~m}^{-2}\right)$. For rainfall, data from GPCP (black), TRMM (red), budget calculation over the DYNAMO northern array (green), and ERA-I (blue) are used. For precipitable water, SSM/I-TMI (black), the DYNAMO northern array (green), and ERA-I (blue) are displayed, while the sounding array (green) and ERA-I (blue) are shown for column-integrated MSE. All variables are 5-day moving averages. Note that the column integration means a mass-weighted integration from 1000 to $100 \mathrm{hPa}$.

a shift to more eastward zonal winds during the passage of the water vapor and precipitation maxima is apparent, as expected during MJO active phases. At the longitudes near the array between $70^{\circ}$ and $90^{\circ} \mathrm{E}$, the easterlies beginning after 16 October, preceding the first active MJO phase, were themselves preceded by westerly anomalies in the first half of the month; these westerlies, unlike those of the MJO events to follow, were not associated with significant precipitation.

Figure 2a shows time series of precipitation averaged over the northern sounding array. Data from the GPCPv1.2 and TRMM 3B42v7 products, the rainfall deduced from budget analysis of the sounding array, and the ERA-I are shown. There is broad agreement, but there are significant discrepancies in detail. The ERA-I is the largest outlier, with precipitation values greater than those in the other datasets during the suppressed periods and considerably smaller than the others during the first active phase in late October.

Figure $2 \mathrm{~b}$ shows column-integrated precipitable water retrieved from the SSM/I-TMI microwave satellite datasets, as well as that computed from the soundings from ERA-I. Again, there is qualitative agreement, but quantitative differences. The sounding values are highest for most of the record while the ERA-I values are lowest, with differences exceeding $5 \mathrm{~mm}$ in early 
a) Source terms

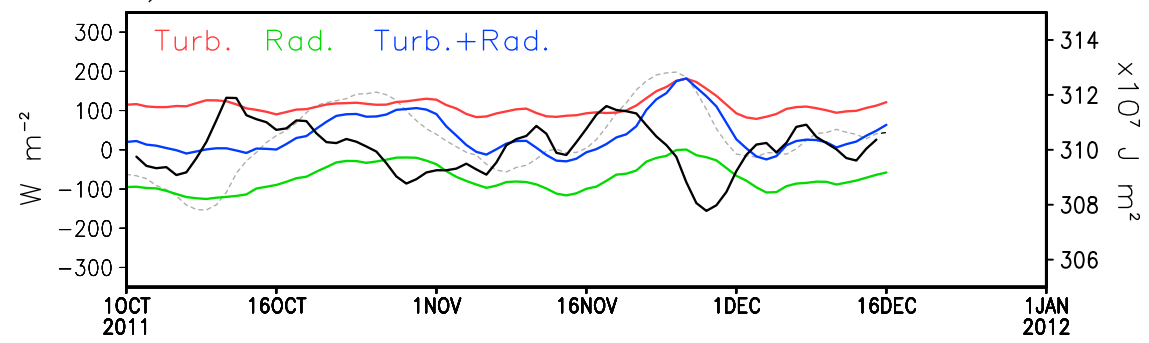

b) Advective terms

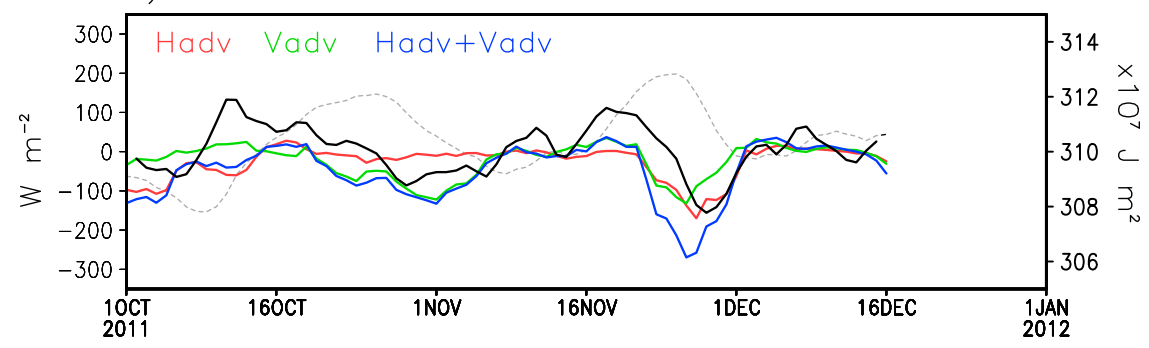

c) Source \& Advective terms

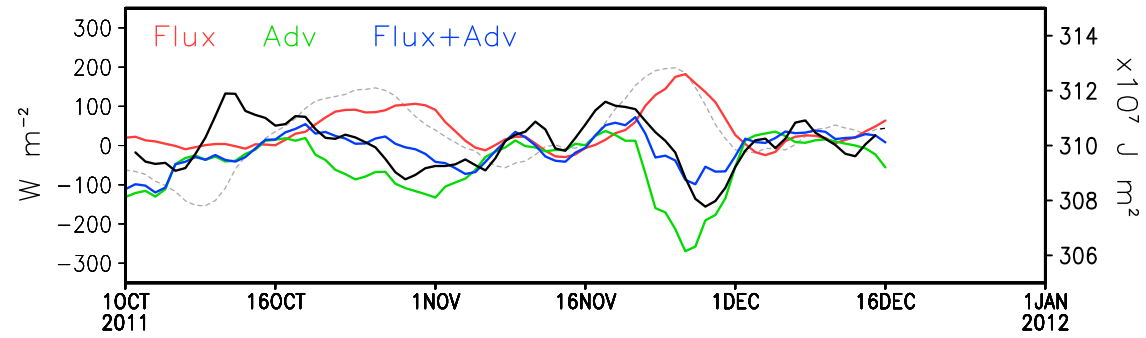

FIG. 3. Column-integrated MSE budget terms derived from the DYNAMO NSA. (a) Source terms: surface turbulent flux (red), column-integrated radiative flux (green), and their sum (blue). (b) Advective terms: horizontal advection (red), vertical advection (green), and their sum (blue). (c) Source and advective terms: sum of all source terms (red), sum of all advective terms (green), and sum of all source and advective terms (blue). All variables are 5-day moving averages. Dotted gray and solid black curves in each panel represent column-integrated MSE (with the vertical axis on the right) and its time derivatives, respectively.

October. It is interesting that ERA-I has simultaneously the driest atmosphere and the most precipitation during suppressed periods.

Figure 2c shows column-integrated moist static energy from the soundings and ERA-I. Time variation of the column-integrated moist static energy closely matches that of precipitable water, indicating that the variations in the latent heat term $L_{v} q$ are much larger than those in the temperature term $c_{p} T$ or the geopotential $g z$.

Figures 3 and 4 show time series of terms in the column-integrated moist static energy budget of the DYNAMO northern array. In Fig. 3, the advection terms are computed from the sounding array data, the surface turbulent fluxes from OAFlux, and the columnintegrated radiative heating (surface flux minus top-of-atmosphere flux, shortwave and longwave combined) from CERES. In Fig. 4, all terms are computed from ERA-I. In each figure, the column-integrated moist static energy itself is also shown for reference, as is its time derivative.

Figures $3 \mathrm{a}$ and $4 \mathrm{a}$ show the total surface turbulent heat flux (latent plus sensible), the column-integrated radiative heating, and their sum. The sum varies approximately in phase with the MSE itself, in quadrature with the tendency. In the first MJO active phase, the radiative heating anomaly is much larger than the surface turbulent flux anomaly. In the second, the anomalies in the two are comparable. In this second event, the increase in radiative heating is more gradual, and begins earlier than, the increase in MSE itself, suggesting that 
a) Source terms

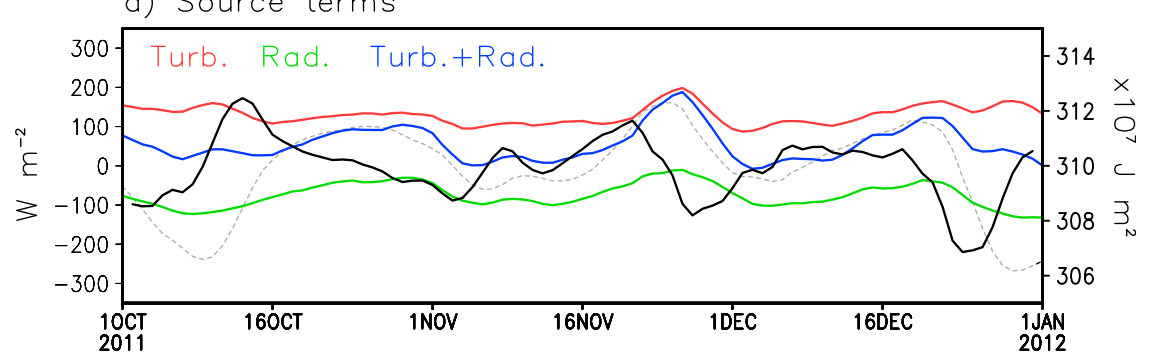

b) Advective terms

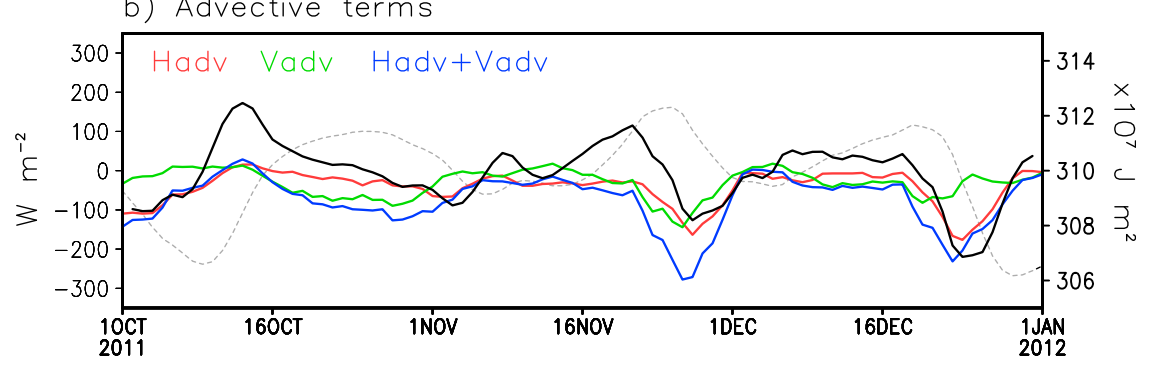

c) Source \& Advective terms

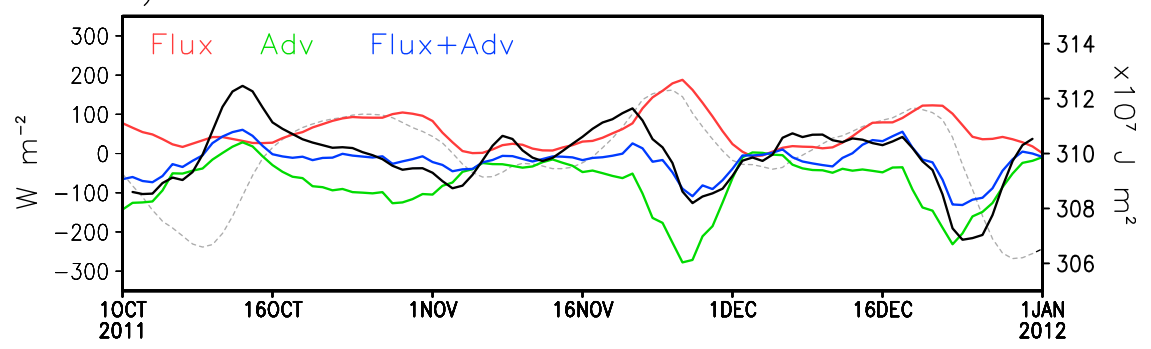

FIG. 4. As in Fig. 3, but for those derived using ERA-I.

radiation contributed significantly to the buildup of the active phase. Similarly gradual increases of columnintegrated radiative heating (decrease of radiative cooling) were found during Tropical Ocean and Global Atmosphere Coupled Ocean-Atmosphere Response Experiment (TOGA COARE) by Johnson and Ciesielski (2000). One plausible cause for the increase (R. Johnson 2014, personal communication) could be the increase in cirrus that has been found, in recent satellite observations, to precede active MJO phases (Virts and Wallace 2010; Del Genio et al. 2012). Such an increase could contribute to the buildup of moisture prior to active phase onset by reducing the rate of radiatively controlled subsidence drying in clear skies (Chikira 2014). Cirrus observations from the R/V Mirai, in the Southern Hemisphere, are analyzed by Suzuki et al. (2013); we are not aware of research to date on cirrus in the NSA region (where the MJO was more active) during the experiment.
Figures $3 \mathrm{~b}$ and $4 \mathrm{~b}$ show column-integrated horizontal advection and vertical advection of MSE, as well as their sum. The sum varies approximately in phase with the tendency of column-integrated MSE, close to in quadrature with the MSE itself. In the first half of October, horizontal advection increased dramatically as the monsoon westerlies decreased, eventually becoming easterly over the eastern equatorial Indian Ocean (as shown in Figs. 6d, 7d, and 10). The subsequent decrease in total advection (horizontal plus vertical) over the course of the active phase in late October was in large part due to vertical advection. In the second MJO event, vertical advection contributed more of the increase in total advection just before the active phase in the sounding data (Fig. 3b) while an advective contribution to the increase then is difficult to detect in the ERA-I (Fig. 4b). In both datasets, both horizontal and vertical advection contributed to the strong decrease after the peak MSE. 
Northern array $(73-80 \mathrm{E}$, Eq. $-5 \mathrm{~N})$

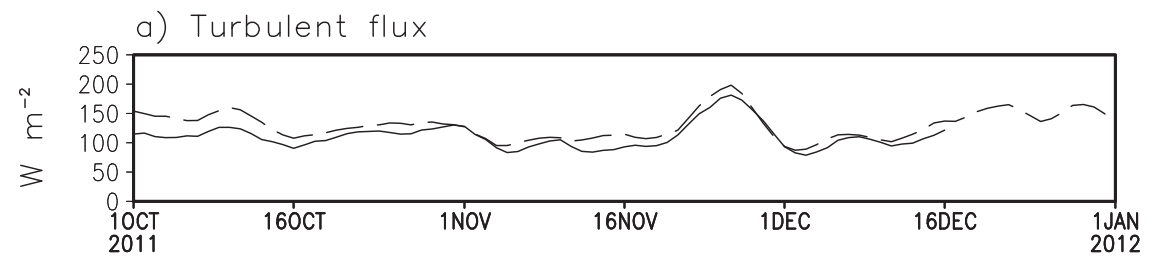

b) Radiative flux

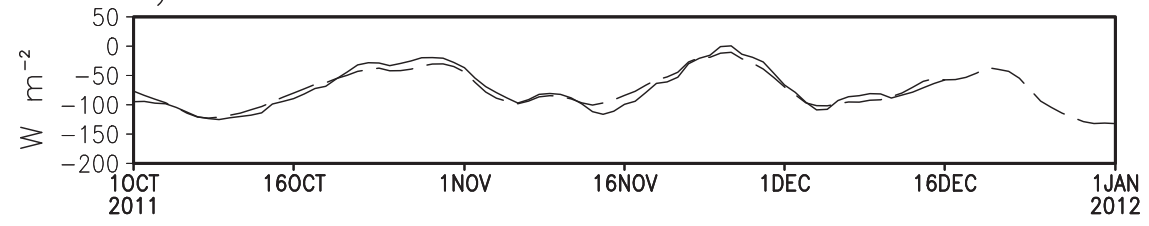

c) Horizontal advection

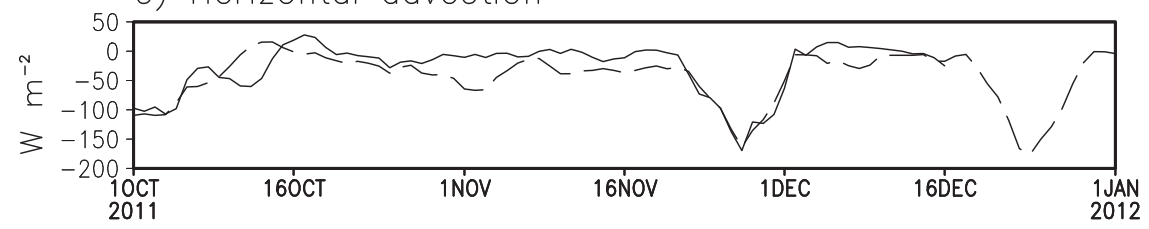

d) Vertical advection

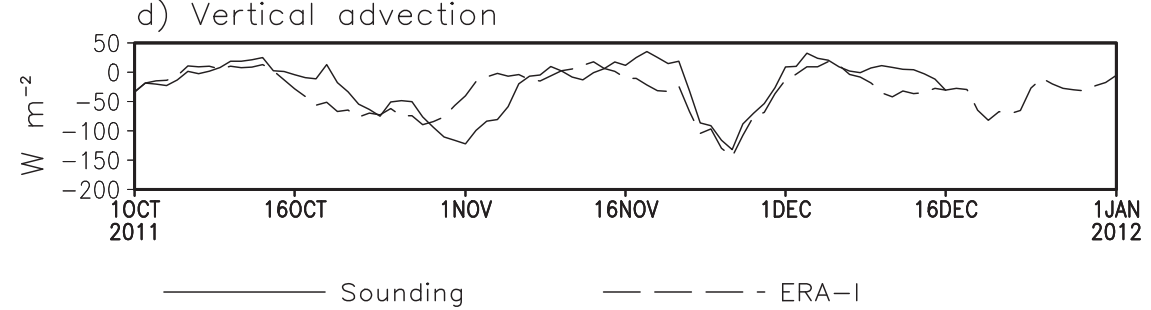

FIG. 5. Column-integrated MSE budget terms $\left(\mathrm{W} \mathrm{m}^{-2}\right)$ derived from the DYNAMO NSA (solid) and ERA-I (dashed). (a) Surface turbulent flux, (b) column-integrated radiative flux, (c) horizontal advection, and (d) vertical advection term. All variables are 5-day moving averages.

Figures $3 \mathrm{c}$ and $4 \mathrm{c}$ compare the sum of the surface fluxes and radiative heating with the sum of vertical and horizontal advection, as well of the sum of all these terms. In Fig. 3c, the sum is similar to the actual tendency in the second event, both in structure and amplitude, though the amplitude is slightly low compared to the actual tendency. In the first event, the sum does not explain the sharp peak in the tendency before 16 October, corresponding to the rapid increase in MSE during that time, although it does capture the steady decrease after that. In Fig. 4c, there is more of a maximum in early October in the sum, but less of a clear decrease after that. In November, the buildup is less well captured than in Fig. 3c, but the drying in the decline of the active phase is about equally evident, again modestly weaker than the observed tendency.

Figure $4 \mathrm{c}$ also shows the third MJO event (not captured in the sounding data) in the ERA-I data. In that event, surface fluxes and radiation both vary in phase with MSE, peaking near the peak of MSE itself, while advection drives the decrease late in the active phase. There is again a conspicuous gap between the actual tendency in the buildup and the sum of sources and advection, particularly in early December. As with the second event, the radiative heating appears to begin increasing early, contributing to the buildup; in this case, however, surface turbulent fluxes increase during that time as well.

Figure 5 compares individual terms computed from the observational datasets with those from ERA-I. The agreement broadly is good. The advection terms show the greatest differences, particularly in the first event. The horizontal advection increases earlier and the vertical advection decreases earlier in ERA-I; the minimum in the vertical advection is stronger as well as later in the sounding data. The turbulent flux is greater in ERA-I 
(a) Omega (hPa/h)

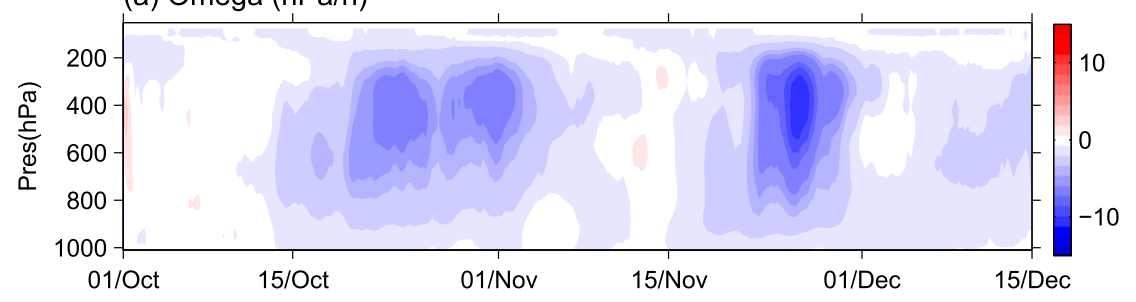

(b) $-\Omega \cdot \mathrm{dh} / \mathrm{dp}(\mathrm{J} / \mathrm{Kg} / \mathrm{s})$
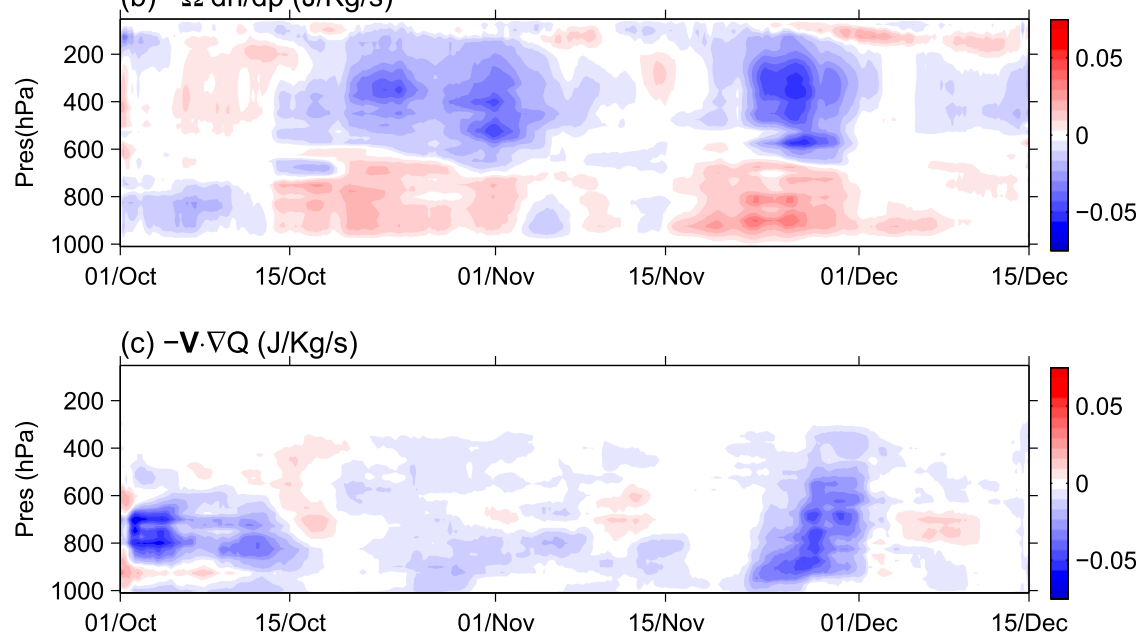

(d) Zonal winds $(\mathrm{m} / \mathrm{s})$

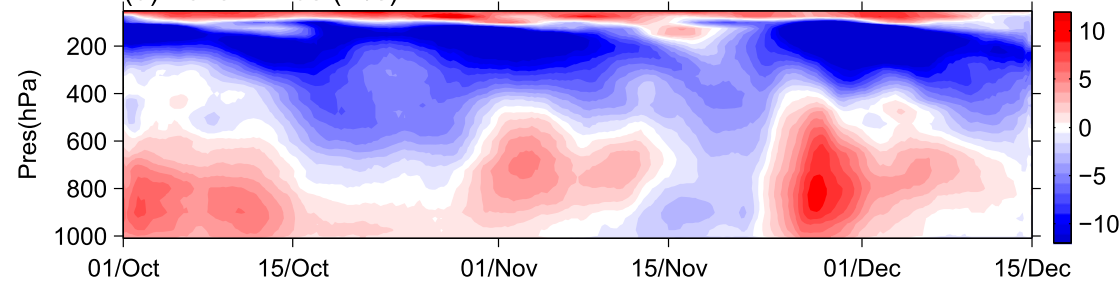

FIG. 6. Time series of (a) pressure velocity $\left(\mathrm{hPa} \mathrm{h}^{-1}\right)$, (b) vertical and (c) horizontal advection of MSE $\left(\mathrm{J} \mathrm{kg}^{-1} \mathrm{~s}^{-1}\right)$, and (d) zonal wind $\left(\mathrm{m} \mathrm{s}^{-1}\right)$ from the DYNAMO NSA. All variables are 5-day moving averages.

than in OAFlux, particularly in early October, but has very similar temporal structure. Radiative cooling in the two datasets agrees very well.

Figures 6 and 7 show (from top to bottom) timeheight plots of pressure vertical velocity, vertical advection of MSE, horizontal advection of moisture, and zonal velocity in the sounding and ERA-I data. These plots lend some insight into the flow structures that produce the changes in advection over the course of the events.

The vertical velocity shows deep ascent early in both active phases in late October and November. In both events, the ascent becomes more concentrated in the upper troposphere toward the end, around 1 November and 1 December. The vertical advection during the active phases tends to be positive in the lower troposphere and negative in the upper troposphere, as expected in ascending motion from the mean structure of MSE with its middle tropospheric minimum. Though it is perhaps not so easy to discern by eye, the upper-tropospheric negative advection becomes stronger relative to the lower tropospheric positive advection as the ascent becomes more concentrated in the upper troposphere late in each event. This corresponds to a more positive normalized gross moist stability, shown more explicitly below.

The horizontal advection variations are dominated by the layer roughly from 900 to $600 \mathrm{hPa}$ in both datasets. Both show strong drying by westerlies in that layer in early October, moistening in mid-October as the easterlies descend into the lower midtroposphere (perhaps as a result of convective momentum transport; e.g., 
(a) Omega (hPa/h)
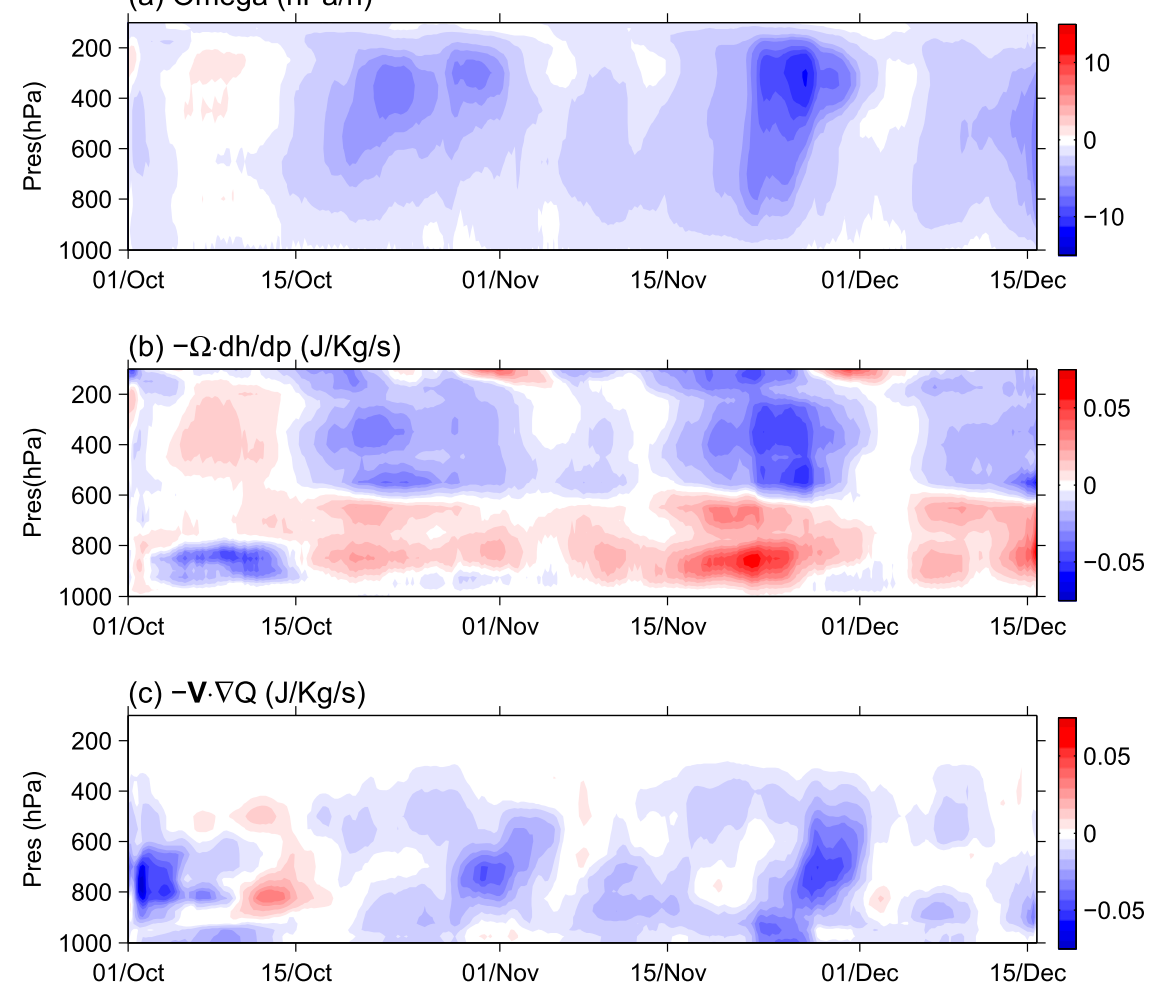

(d) Zonal winds $(\mathrm{m} / \mathrm{s})$

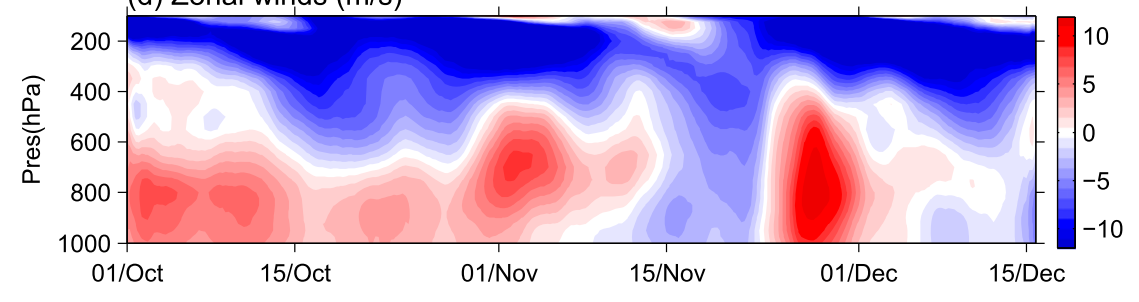

FIG. 7. Area-averaged $\left(0^{\circ}-5^{\circ} \mathrm{N}, 73^{\circ}-80^{\circ} \mathrm{E}\right)$ time series of (a) pressure velocity $\left(\mathrm{hPah}^{-1}\right)$, (b) vertical and (c) horizontal advection of $\operatorname{MSE}\left(\mathrm{J} \mathrm{kg}^{-1} \mathrm{~s}^{-1}\right)$, and (d) zonal wind $\left(\mathrm{m} \mathrm{s}^{-1}\right)$ from ERA-I. All variables are 5-day moving averages.

Miyakawa et al. 2012) and the westerlies near the surface weaken (much more so in the sounding data than ERA-I), followed by a return of drying around 1 November. Both show a similar pattern in the second event; the horizontal advective moistening is not as dramatic in late November as in mid-October, but there is at least a reduction in advective drying; later in the event, just before 1 December, the intense westerly wind burst brings very strong advective drying through a deep layer, from $400 \mathrm{hPa}$ down to near the surface (reaching the surface, in fact, in the sounding data). The role of horizontal advection in bringing about the end of the active phases was discussed earlier by Kerns and Chen (2014).

Figures 8 and 9 analyze the moist static energy budget using the NGMS, defined and discussed in section $2 b$.
The NGMS has horizontal and vertical components, in which only the horizontal or vertical component of MSE advection is used in the numerator; the total NGMS is the sum of the two. Each column shows the horizontal, vertical, and total NGMS as a function of time. The column-integrated MSE itself is also shown for reference, to indicate the active and suppressed MJO phases.

Figure 8 computes the NGMS from the sounding data and other observational datasets. Two curves are shown for NGMS in each panel. In one, the NGMS is derived directly from the advection terms computed with the sounding data, while in the other, it is computed as a budget residual. The difference is one measure of the degree to which the analyzed MSE budget closes. In the budget residual calculation, the OAFlux and CERES data are used for the surface turbulent fluxes and 
a) Vertical

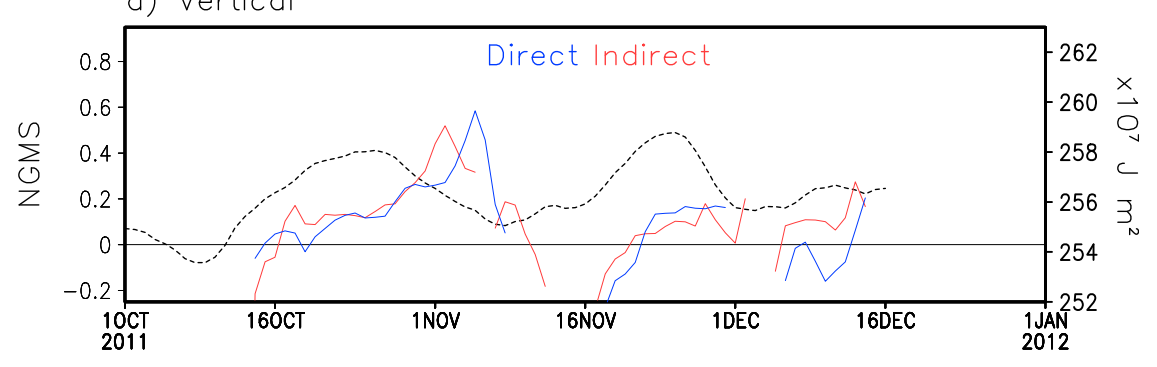

b) Horizontal

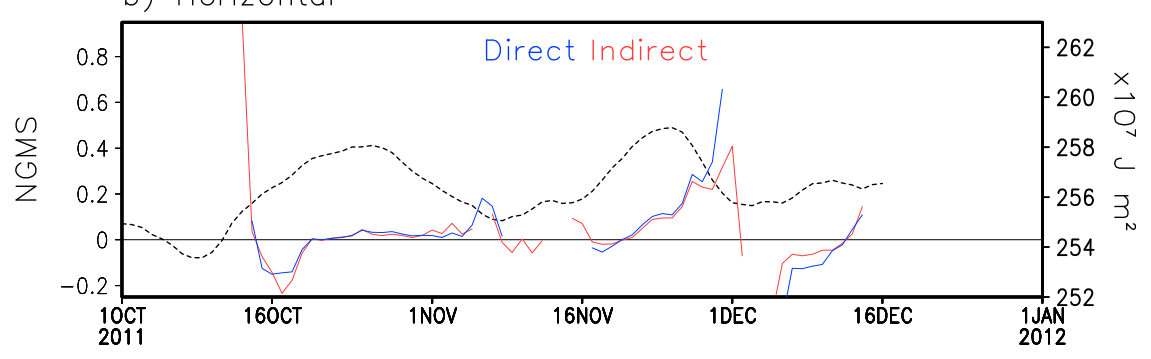

c) Vertical+Horizontal

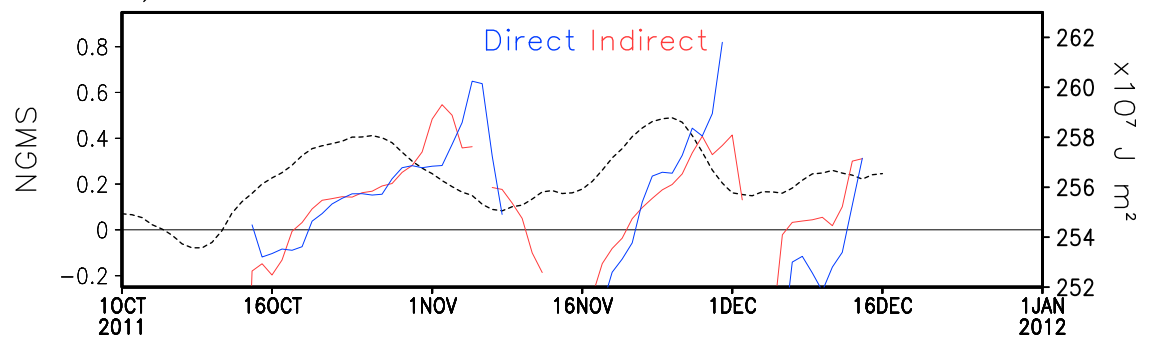

FIG. 8. Estimated NGMS using the DYNAMO NSA. (a) Horizontal, (b) vertical, and (c) horizontal plus vertical component. The blue solid curve denotes NGMS directly estimated from the advection terms, while the red solid curve denotes NGMS indirectly estimated from the budget residual. The black dashed curve shows column-integrated MSE $\left(\times 10^{7} \mathrm{~J} \mathrm{~m}^{-2}\right)$. All variables are 5-day moving averages.

radiative fluxes, respectively, while the tendency is computed from the sounding data. Points at which the denominator is less than one-fifth of the numerator in value are not shown, in order to avoid the neighborhoods near zero crossings of the denominator, at which NGMS is not well defined. Figure 9 shows an analogous set of calculations from the ERA-I data. In all cases, both numerator and denominator are smoothed with a 5-day running mean. In both sets of calculations, both components of the NGMS increase from the suppressed phase to the active phase. The increase in the vertical component is weak in the ERA-I when computed directly, strong when it is computed as a budget residual.

In Fig. 1, we introduced the overall large-scale evolution of the MJO events. Now, having analyzed the moist static energy budget and seen that horizontal advection plays a significant role, we present a further depiction of the horizontal structures in the lowfrequency component of the flow to illustrate the large-scale flow patterns responsible for the horizontal advection. Figure 10 shows a series of maps, each one representing a 5-day mean, of column water vapor, $850-\mathrm{hPa}$ horizontal vector wind, and precipitation. Precipitation is contoured only at intervals of $10 \mathrm{~mm}_{\text {day }}{ }^{-1}$, to make more apparent when and where the active phases of the MJO occur. In showing 850-hPa wind, we take this to be representative of the lower-level wind that is responsible for the majority of the horizontal advection.

We focus on the bands of latitude in which the MJO's variations in convective activity are most prominent, which lie somewhat north of the equator in October and November, proceeding to south of the equator by December. In these latitude bands, the maps show relatively westerly flow during suppressed phases, 
a) Vertical

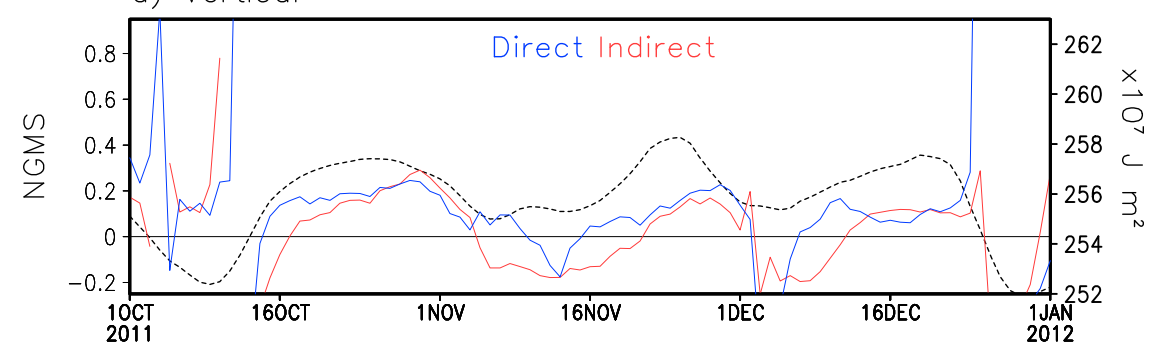

b) Horizontal

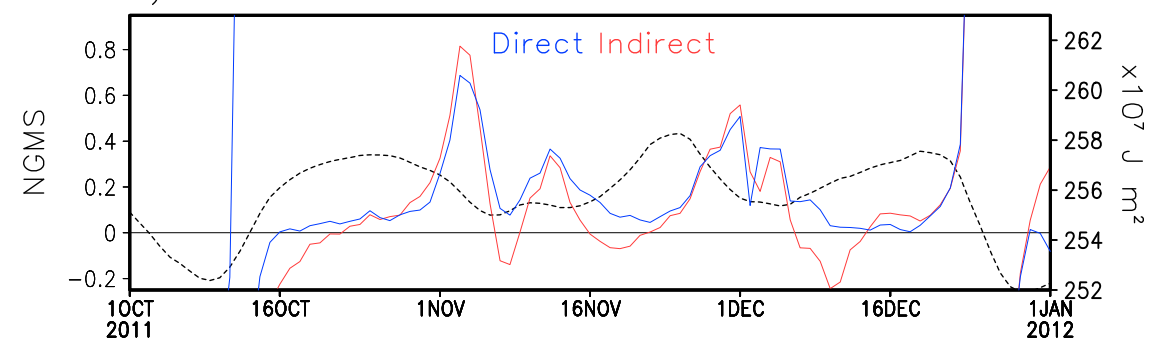

c) Vertical+Horizontal

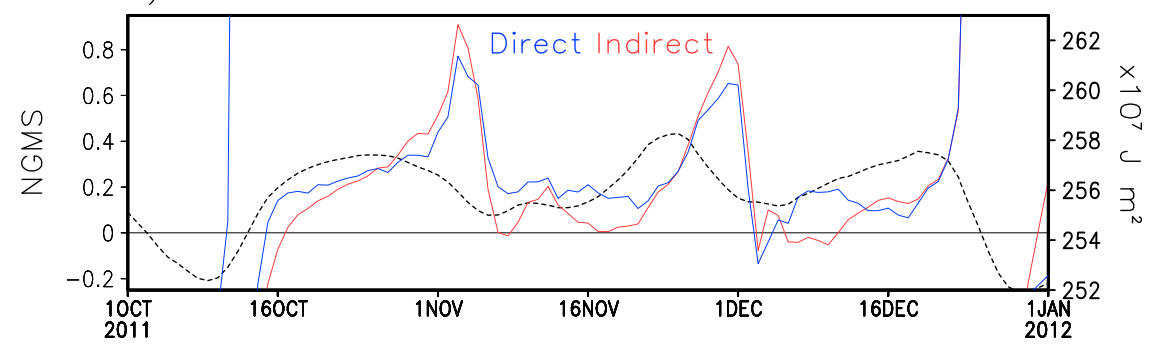

FIG. 9. As in Fig. 8, but using ERA-I.

particularly in the central and eastern longitudes of the Indian Ocean basin-10-14 October, 4-8 November, and 4-10 December (not shown)-compared to the following phases, in which the moisture is increasing. As the active phases mature in the succeeding weeks, strong westerlies redevelop in response to the convection, again bringing in tongues of dry air from the west during 30 October-3 November, 24 November-3 December, and 25-31 December (in the last case, the dry air appears to come more directly from the north than west).

The strong westerlies just north of the equator bringing dry air eastward are apparent during 10-14 October; the cyclonic flow pattern suggests that the source of the dry air is the subtropical Arabian Sea, the Indian subcontinent, and South Asia. Very moist air is present in the Bay of Bengal and South China Sea at this time; the zonal gradient of water vapor north of the equator is strongly positive (increasing eastward). During 15-24 October, the westerlies remain over the western Indian Ocean, but change to easterlies over the eastern Indian Ocean; one has the impression that as the monsoon westerlies relax, easterlies bring the moist air west into the central Indian Ocean. This allows precipitation to increase, maximizing around the Maldives during 25-29 October; during that period, however, the strongest westerlies are found only in the western part of the basin. During 30 October-3 November, the westerlies reach across the near-equatorial Indian Ocean, pushing dry air over the Maldives and suppressing convection. During 9-13 November, when the monsoon is over, strong westerlies are found only in the eastern part of the basin. Column water vapor is relatively low (though still fairly high by the standards of Earth as a whole, with values in excess of $50 \mathrm{~mm}$ around the Maldives), and precipitation is suppressed over the entire equatorial Indian Ocean. On the equator, the zonal gradient of column water vapor is positive. During 14-18 November, stronger easterlies again relax the zonal gradient, bringing moist air westward, preceding the onset of strong convection during 19-23 November. Strong westerlies during 29 November-3 December again bring dry air (whose source again appears to be 

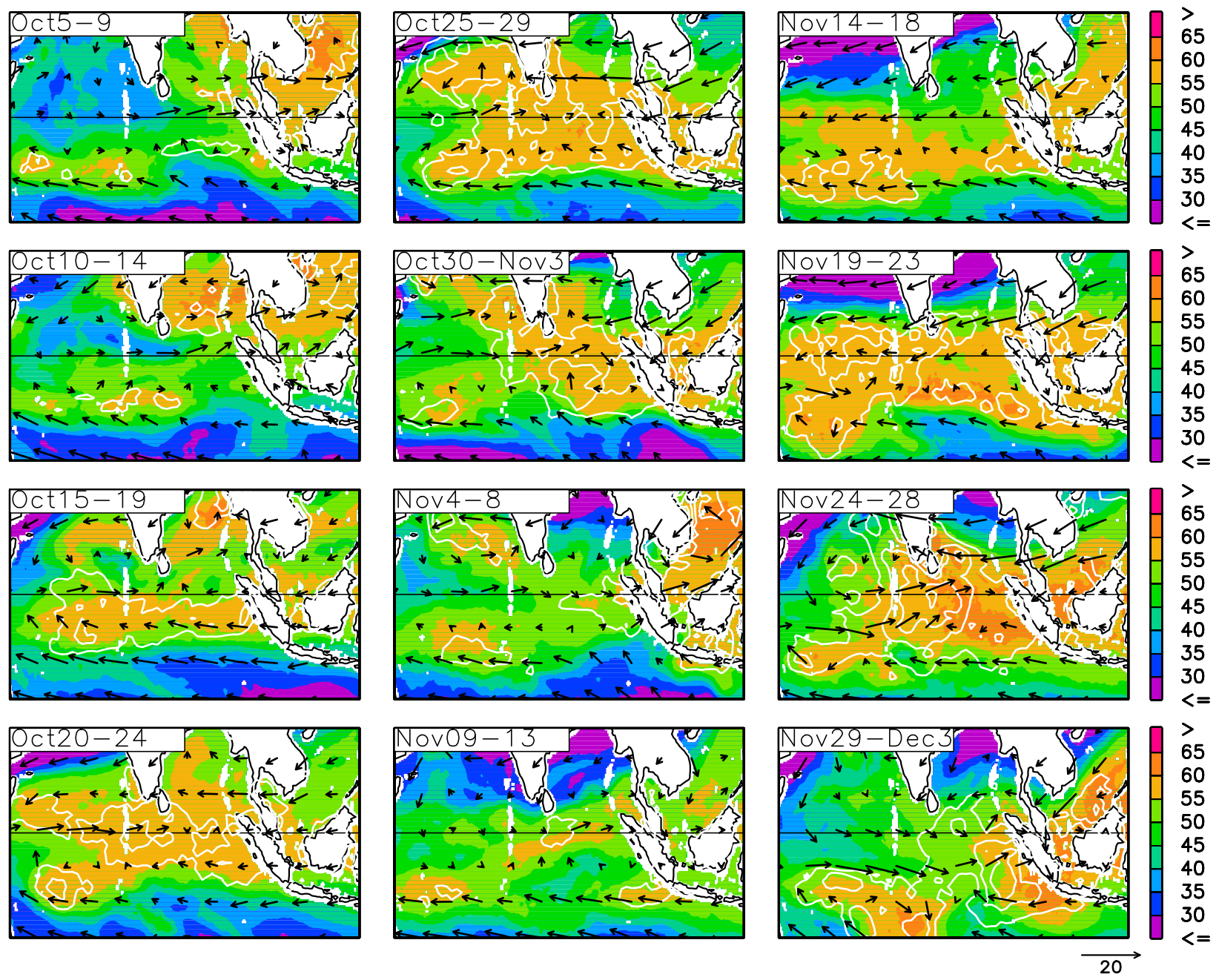

FIG. 10. Map view of 5-day-mean column water vapor (mm, shaded), 850-hPa vector wind ( $\mathrm{m} \mathrm{s}^{-1}$, arrows), and precipitation (mm day ${ }^{-1}$, contour interval $10 \mathrm{~mm}_{\text {day }}{ }^{-1}$; lowest contour value shown is $10 \mathrm{~mm}_{\text {day }}{ }^{-1}$ ).

subtropical, associated with strong equatorward flow near the longitude of the East African coast in both hemispheres) eastward, reestablishing the zonal gradient of water vapor. A similar sequence plays out again in December.

\section{Conclusions}

We have analyzed the moist static energy budget over the sounding array from the CINDY/DYNAMO field campaign, using sounding data, complementary largescale datasets for surface turbulent fluxes and radiative fluxes, and ERA-I data. Three MJO active phases are analyzed, though sounding data are only available for the first two.

The results show some significant differences between the different MJO events, as noted by Johnson and Ciesielski (2013); however, some commonalities are also apparent. It will be valuable to further study the generality of these results using statistics using long-term datasets.

In all events, column water vapor, column moist static energy, and precipitation are strongly correlated, as expected. Column radiative heating is also strongly correlated with those variables. Surface turbulent enthalpy fluxes (predominantly latent heat flux) are also correlated with those variables, with some lag, on average, as expected. The magnitude of turbulent flux variations is more variable from event to event than is the magnitude of radiative flux variations and is smaller than radiative flux variations in two out of the three events.

In all events, horizontal advection is relatively moistening (i.e., more positive than before or after; in some cases positive in absolute value) in the buildup to the active phase. Horizontal advection is drying in the later part of the active phase itself. Large moistening by horizontal advection occurs in the buildup to the 
October event, while large drying by horizontal advection occurs during the rapid decay of the November event. Both of these are consistent with a significant role for horizontal advection in the eastward propagation of the MJO, but in different ways (moistening ahead versus drying behind). The December event is not captured in the sounding data but appears more similar to the November event in the ERA-I data.

The horizontal advection variations result, to some extent, from variations in zonal advection of moisture in the 600-900-hPa layer, although the ultimate source of the dry air appears (by inspection of maps) to be subtropical, so that meridional advection is clearly important as well. In the wake of the December active phase, the dry advection appears to be more meridional than zonal. To the extent that the source of the dry air is subtropical in either case, and because of off-equatorial cyclonic gyres lagging the active phase, this suggests that the fundamental mechanism is the same whether the zonal or meridional wind accomplishes the advection. The relative magnitudes of horizontal and vertical advection also vary across the MJO events, but the picture that emerges overall is of a significant role for both in MJO propagation. Analysis of the normalized gross moist stability shows particularly clearly the increase in vertical advection from suppressed to peak active phase. This appears to result from a deepening layer of ascent as the active phase matures.

Overall, these results support the view that the moist static energy anomalies associated with the MJO are maintained by radiative feedbacks, with surface flux feedbacks also playing a significant but perhaps secondary role, and that those anomalies propagate because of advection. Though the advection is both horizontal and vertical, we speculate on theoretical grounds that the horizontal advection plays a more fundamental role in determining the direction of propagation. The $\beta$ effect breaks the symmetry between east and west, and that is most clearly evident in the horizontal flow field, for example, as manifested in the response to a stationary heat source (Webster 1972; Gill 1980) to which the MJO's flow pattern bears some broad resemblance. While the increase of the vertical NGMS with time during the course of an MJO active phase (shown in Figs. 8 and 9) also is associated with relative moistening during onset and relative drying during decay of the active phase, and thus aids propagation, we see no inherent reason why that same progression could not occur for a westward-propagating disturbance.

Broadly, our conclusions are consistent with our expectations from previous work, as described in section 1 , but show to what degree those expectations (derived mostly from statistical and modeling studies) are met in a small set of specific, well-observed events. Nuances apparent from this small set of events that are not immediately apparent from statistical studies are as follows.

1) The sounding array and ERA-I datasets yield similar results at the level of detail pursued here. This is encouraging from the point of view of using reanalysis datasets for further studies.

2) Though variations in radiation and surface turbulent fluxes both contribute to the maintenance of columnintegrated moist static energy anomalies, radiation on balance appears to be the more important process; this is consistent also with theoretical arguments given by Sobel and Maloney (2013).

3) Radiative heating begins to increase well before the peak of the active phase, as also found in TOGA COARE (Johnson and Ciesielski 2000). The speculation that cirrus may be involved in this will require further investigation.

4) Both horizontal and vertical advection play quantitatively comparable roles in propagation of the MJO active phases (though we argue that horizontal advection is more likely to be responsible for the selection of eastward as opposed to westward propagation).

Acknowledgments. SSM/I and TMI data are produced by Remote Sensing Systems and sponsored by the NASA Earth Science MEaSUREs DISCOVER Project. Data are available at www.remss.com. We thank Richard Johnson and Paul Ciesielski for the sounding data and for discussions. This work was supported by National Science Foundation Grant AGS-1062206 and Office of Naval Research Grant N00014-415 12-1-0911. DK was supported by the NASA Grant NNX13AM18G and the Korea Meteorological Administration Research and Development Program under Grant CATER 2013-3142.

\section{REFERENCES}

Adler, R. F., and Coauthors, 2003: The version 2 Global Precipitation Climatology Project (GPCP) Monthly Precipitation Analysis (1979-present). J. Hydrometeor., 4, 1147-1167, doi:10.1175/1525-7541(2003)004<1147:TVGPCP > 2.0.CO;2.

Andersen, J. A., and Z. Kuang, 2012: Moist static energy budget of MJO-like disturbances in the atmosphere of a zonally symmetric aquaplanet. J. Climate, 25, 2782-2804, doi:10.1175/ JCLI-D-11-00168.1.

Back, L. E., and C. S. Bretherton, 2006: Geographic variability in the export of moist static energy and vertical motion profiles in the tropical Pacific. Geophys. Res. Lett., 33, L17810, doi:10.1029/2006GL026672.

Benedict, J. J., E. D. Maloney, A. H. Sobel, and D. M. W. Frierson, 2014: Gross moist stability and MJO simulation skill in three full-physics GCMs. J. Atmos. Sci., 71, 3327-3349, doi:10.1175/ JAS-D-13-0240.1. 
Betts, A. K., 1974: Further comments on "A comparison of the equivalent potential temperature and the static energy." J. Atmos. Sci., 31, 1713-1715, doi:10.1175/1520-0469(1974)031<1713: FCOCOT>2.0.CO;2.

Bony, S., and K. A. Emanuel, 2005: On the role of moist processes in tropical intraseasonal variability: Cloud-radiation and moisture-convection feedbacks. J. Atmos. Sci., 62, 2770-2789, doi:10.1175/JAS3506.1.

Chikira, M., 2014: Eastward-propagating intraseasonal oscillation represented by Chikira-Sugiyama cumulus parameterization. Part II: Understanding moisture variation under weak temperature gradient balance. J. Atmos. Sci., 71, 615-639, doi:10.1175/JAS-D-13-038.1.

Ciesielski, P. E., and Coauthors, 2014: Quality-controlled upperair sounding dataset for DYNAMO/CINDY/AMIE: Development and corrections. J. Atmos. Oceanic Technol., 31, 741-764, doi:10.1175/JTECH-D-13-00165.1.

Dee, D. P., and Coauthors, 2011: The ERA-Interim reanalysis: Configuration and performance of the data assimilation system. Quart. J. Roy. Meteor. Soc., 137, 553-597, doi:10.1002/qj.828.

Del Genio, A. D., Y. Chen, D. Kim, and M.-S. Yao, 2012: The MJO transition from shallow to deep convection in CloudSat/ CALIPSO data and GISS GCM simulations. J. Climate, 25, 3755-3770, doi:10.1175/JCLI-D-11-00384.1.

Emanuel, K. A., 1987: An air-sea interaction model of intraseasonal oscillations in the tropics. J. Atmos. Sci., 44, 2324-2340, doi:10.1175/1520-0469(1987)044<2324:AASIMO>2.0.CO;2.

Fuchs, Z., and D. J. Raymond, 2002: Large-scale modes of a nonrotating atmosphere with water vapor and cloud-radiation feedbacks. J. Atmos. Sci., 59, 1669-1679, doi:10.1175/ 1520-0469(2002)059<1669:LSMOAN>2.0.CO;2.

$\longrightarrow$, and _ 2005: Large-scale modes in a rotating atmosphere with radiative-convective instability and WISHE. J. Atmos. Sci., 62, 4084-4094, doi:10.1175/JAS3582.1.

— ical disturbances with a humidity closure. Tellus, 59A, 344354, doi:10.1111/j.1600-0870.2007.00230.x.

Gill, A. E., 1980: Some simple solutions for heat induced tropical circulations. Quart. J. Roy. Meteor. Soc., 106, 447-462, doi:10.1002/qj.49710644905.

Gottschalck, J., P. Roundy, C. Schreck, A. Vintzileos, and C. Zhang, 2013: Large-scale atmospheric and oceanic conditions during the 2011-12 DYNAMO field campaign. Mon. Wea. Rev., 141, 4173-4196, doi:10.1175/MWR-D-13-00022.1.

Huffman, G. J., R. F. Adler, D. T. Bolvin, and G. Gu, 2009: Improving the global precipitation record: GPCP version 2.1. Geophys. Res. Lett., 36, L17808, doi:10.1029/2009GL040000.

Johnson, R. H., and P. E. Ciesielski, 2000: Rainfall and radiative heating rates from TOGA COARE atmospheric budgets. J. Atmos. Sci., 57, 1497-1514, doi:10.1175/ 1520-0469(2000)057<1497:RARHRF $>2.0$. CO;2.

— oscillations deduced from DYNAMO sounding arrays. J. Atmos. Sci., 70, 3157-3179, doi:10.1175/JAS-D-13-065.1.

Julian, P. R., and R. A. Madden, 1981: Comments on a paper by $\mathrm{T}$. Yasunari, a quasi-stationary appearance of 30 to 40-day period in the cloudiness fluctuations during the summer monsoon over India. J. Meteor. Soc. Japan, 59, 435-437.

Kerns, B. W., and S. S. Chen, 2014: Equatorial dry air intrusion and related synoptic variability in MJO initiation during DYNAMO. Mon. Wea. Rev., 142, 1326-1343, doi:10.1175/ MWR-D-13-00159.1.
Kim, D., J.-S. Kug, and A. H. Sobel, 2014: Propagating vs. nonpropagating Madden-Julian oscillation events. J. Climate, 27, 111-125, doi:10.1175/JCLI-D-13-00084.1.

Kiranmayi, L., and E. D. Maloney, 2011: Intraseasonal moist static energy budget in reanalysis data. J. Geophys. Res., 116, D21117, doi:10.1029/2011JD016031.

Lin, J., and B. E. Mapes, 2004: Radiation budget of the tropical intraseasonal oscillation. J. Atmos. Sci., 61, 2050-2062, doi:10.1175/1520-0469(2004)061<2050:RBOTTI>2.0.CO;2.

Loeb, N. G., S. Kato, W. Su, T. Wong, F. G. Rose, D. R. Doelling, J. R. Norris, and X. Huang, 2012: Advances in understanding top-ofatmosphere radiation variability from satellite observations. Surv. Geophys., 33, 359-385, doi:10.1007/s10712-012-9175-1.

Ma, D., and Z. Kuang, 2011: Modulation of radiative heating by the Madden-Julian oscillation. Geophys. Res. Lett., 38, L21813, doi:10.1029/2011GL049734.

Madden, R. A., and P. R. Julian, 1971: Detection of a 40-50 day oscillation in the zonal wind in the tropical Pacific. J. Atmos. Sci., 28, 702-708, doi:10.1175/1520-0469(1971)028<0702: DOADOI $>2.0 . \mathrm{CO} ; 2$.

—_, and ——, 1972: Description of global-scale circulation cells in the tropics with a 40-50 day period. J. Atmos. Sci., 29, 1109-1123, doi:10.1175/1520-0469(1972)029<1109: DOGSCC $>2.0 . \mathrm{CO} ; 2$.

Majda, A. J., and S. N. Stechmann, 2009: The skeleton of tropical intraseasonal oscillations. Proc. Natl. Acad. Sci. USA, 106, 8417-8422, doi:10.1073/pnas.0903367106.

Maloney, E. D., 2009: The moist static energy budget of a composite tropical intraseasonal oscillation in a climate model. J. Climate, 22, 711-729, doi:10.1175/2008JCLI2542.1.

Miyakawa, T., Y. N. Takayabu, T. Nasuno, H. Miura, M. Satoh, and M. W. Moncrieff, 2012: Convective momentum transport by rainbands within a Madden-Julian oscillation in a global nonhydrostatic model with explicit deep convective processes. Part I: Methodology and general results. J. Atmos. Sci., 69, 1317-1338, doi:10.1175/JAS-D-11-024.1.

Neelin, J. D., 2007: Moist dynamics of tropical convection zones in monsoons, teleconnections, and global warming. The Global Circulation of the Atmosphere, T. Schneider and A. H. Sobel, Eds., Princeton University Press, 267-301.

_ , and I. M. Held, 1987: Modeling tropical convergence based on the moist static energy budget. Mon. Wea. Rev., 115, 3-12, doi:10.1175/1520-0493(1987)115<0003:MTCBOT>2.0.CO;2.

,$- \ldots$, and K. H. Cook, 1987: Evaporation-wind feedback and low-frequency variability in the tropical atmosphere. J. Atmos. Sci., 44, 2341-2348, doi:10.1175/1520-0469(1987)044<2341: EWFALF $>2.0 . \mathrm{CO} ; 2$.

Powell, S. W., and R. A. Houze Jr., 2013: The cloud population and onset of the Madden-Julian Oscillation over the Indian Ocean during DYNAMO-AMIE. J. Geophys. Res., 118, 1197911995, doi:10.1002/2013JD020421.

Raymond, D. J., 2001: A new model of the Madden-Julian oscillation. J. Atmos. Sci., 58, 2807-2819, doi:10.1175/ 1520-0469(2001)058<2807:ANMOTM>2.0.CO;2.

— Julian oscillation. J. Climate, 22, 3031-3046, doi:10.1175/ 2008JCLI2739.1.

—, S. Sessions, A. H. Sobel, and Z. Fuchs, 2009: The mechanics of gross moist stability. J. Adv. Model. Earth Syst., 1, doi:10.3894/JAMES.2009.1.9.

Sobel, A. H., and E. D. Maloney, 2012: An idealized semi-empirical framework for modeling the Madden-Julian oscillation. J. Atmos. Sci., 69, 1691-1705, doi:10.1175/JAS-D-11-0118.1. 
and -2013 : Moisture modes and the eastward propagation of the MJO. J. Atmos. Sci., 70, 187-192, doi:10.1175/ JAS-D-12-0189.1.

,$-\ldots$, G. Bellon, and D. M. Frierson, 2008: The role of surface fluxes in tropical intraseasonal oscillations. Nat. Geosci., 1, 653-657, doi:10.1038/ngeo312.

,,--- , and,- 2010 : Surface fluxes and tropical intraseasonal variability: A reassessment. J. Adv. Model. Earth Syst., 2, doi:10.3894/JAMES.2010.2.2.

Sugiyama, M., 2009a: Moisture mode in the tropics. Part I: Analysis based on the weak temperature gradient approximation. J. Atmos. Sci., 66, 1507-1523, doi:10.1175/2008JAS2690.1.

,$- 2009 \mathrm{~b}$ : Moisture mode in the tropics. Part II: Nonlinear behavior on an equatorial $\beta$-plane. J. Atmos. Sci., 66, 1525-1542, doi:10.1175/2008JAS2691.1.

Sukhatme, J., 2014: Low-frequency modes in an equatorial shallow-water model with moisture gradients. Quart. J. Roy. Meteor. Soc., 140, 1838-1846, doi:10.1002/qj.2264.

Suzuki, J., M. Fujiwara, T. Nishizawa, R. Shirooka, K. Yoneyama, M. Katsumata, I. Matsui, and N. Sugimoto, 2013: The occurrence of cirrus clouds associated with eastward propagating equatorial $n=0$ inertio-gravity and Kelvin waves in November 2011 during the CINDY2011/DYNAMO campaign. J. Geophys. Res. Atmos., 118, 12941-12947, doi:10.1002/2013JD019960.

Virts, K. S., and J. M. Wallace, 2010: Annual, interannual, and intraseasonal variability of tropical tropopause transition layer cirrus. J. Atmos. Sci., 67, 3097-3112, doi:10.1175/ 2010JAS3413.1.

Wang, B., 1988: Dynamics of tropical low-frequency waves: An analysis of the moist Kelvin wave. J. Atmos. Sci., 45, 2051-2065, doi:10.1175/1520-0469(1988)045<2051:DOTLFW>2.0.CO;2.
Webster, P. J., 1972: Response of the tropical atmosphere to local, steady forcing. Mon. Wea. Rev., 100, 518-541, doi:10.1175/ 1520-0493(1972) $100<0518$ :ROTTAT $>2.3$.CO;2.

Wielicki, B. A., B. R. Barkstrom, E. F. Harrison, R. B. Lee III, G. L. Smith, and J. E. Cooper, 1996: Clouds and the Earth's Radiant Energy System (CERES): An Earth observing system experiment. Bull. Amer. Meteor. Soc., 77, 853-868, doi:10.1175/1520-0477(1996)077<0853:CATERE>2.0.CO;2.

Yasunaga, K., and B. E. Mapes, 2012: Differences between moredivergent vs. more-rotational types of convectively coupled equatorial waves. Part I: Space-time spectral analyses. $J$. Atmos. Sci., 69, 3-16, doi:10.1175/JAS-D-11-033.1.

Yoneyama, K., C. Zhang, and C. N. Long, 2013: Tracking pulses of the Madden-Julian oscillation. Bull. Amer. Meteor. Soc., 94, 1871-1891, doi:10.1175/BAMS-D-12-00157.1.

Yu, L., X. Jin, and R. A. Weller, 2008: Multidecade Global Flux Datasets from the Objectively Analyzed Air-Sea Fluxes (OAFlux) Project: Latent and sensible heat fluxes, ocean evaporation, and related surface meteorological variables. OAFlux Project Tech. Rep. OA-2008-01, Woods Hole Oceanographic Institution, Woods Hole, MA, 64 pp. [Available online at http://oaflux.whoi.edu/pdfs/OAFlux TechReport_3rd_release.pdf.]

Zhang, C., J. Gottschalck, E. D. Maloney, M. W. Moncrieff, F. Vitart, D. E. Waliser, B. Wang, and M. C. Wheeler, 2013: Cracking the MJO nut. Geophys. Res. Lett., 40, 1223-1230, doi:10.1002/grl.50244.

Zuluaga, M. D., and R. A. Houze Jr., 2013: Evolution of the population of precipitating convective systems over the equatorial Indian Ocean in active phases of the Madden-Julian oscillation. J. Atmos. Sci., 70, 2713-2725, doi:10.1175/ JAS-D-12-0311.1. 